Laser Chem., Vol.16, pp. 157-166

Reprints available directly from the publisher

Photocopying permitted by license only
(C) 1996 OPA (Overseas Publishers Association) Amsterdam B.V. Published in The Netherlands by Harwood Academic Publishers GmbH Printed in Malaysia

\title{
MULTIPHOTON DISSOCIATION OF PHENYLSILANE UPON EXCITATION AT 212.5 NM
}

\author{
MOHAMED OUJJA, MARGARITA MARTÍN, \\ REBECA DE NALDA and MARTA CASTILLEJO \\ Instituto de Química Física "Rocasolano", CSIC, \\ Serrano 119, 28006 Madrid, Spain
}

(Received 26 July, 1995)

\begin{abstract}
The photodissociation processes that follow the photolysis of phenylsilane with a narrow band laser at $212.5 \mathrm{~nm}$ were studied by observing photofragment fluorescence spectra in the 200 to $900 \mathrm{~nm}$ range. Emission from several excited states of $\mathrm{Si}$ atoms was detected together with emissions from the molecular fragments $\operatorname{SiH}\left(\mathrm{A}^{2} \Delta\right)$ and $\mathrm{C}_{2}\left(\mathrm{~d}^{3} \Pi_{\mathrm{g}}\right)$. Si and $\mathrm{SiH}$ emissions show a quadratic dependence with laser energy whereas dependence for $\mathrm{C}_{2}$ emission is cubic, indicating the participation of two and three photon processes in the formation of the respective fragments. The emission spectra of the molecular fragments provides information about their internal energy content and allows discussion of the possible channels responsible for the appearance of those fragments.
\end{abstract}

KEY WORDS: Phenylsilane, Multiphoton excitation, Photofragmentation.

\section{INTRODUCTION}

The photodissociation processes of phenylsilane, $\mathrm{PhSiH}_{3}$, have recently received much attention partly because this molecule has shown to be a good precursor for silicon film formation by CVD processes. ${ }^{1-3}$ Therefore considerable effort is being dedicated to understand the role of intermediates in the production of $\mathrm{Si}$ atoms and other molecular fragments, and to investigate the possibility of inducing specific photodissociation pathways in the molecule by varying the nature of the initial excitation or the energy of the photon. Despite this effort, information about the exact photofragmentation processes of $\mathrm{PhSiH}_{3}$ in the gas phase, and their dependence with the type and content of the initial excitation, is rather scarce with previous studies concentrating in the IR region ${ }^{1-3}$ and at several wavelengths in the UV below $380 \mathrm{~nm}^{4-8}$ The UV absorption spectrum of the $\mathrm{PhSiH}_{3}$ molecule shows three absorption regions which correspond to the excitation from the ground ${ }^{1} \mathrm{~A}_{\mathrm{lg}}$ state to the ${ }^{1} \mathrm{~B}_{2 \mathrm{u}},{ }^{1} \mathrm{~B}_{1 \mathrm{u}}$ and ${ }^{1} \mathrm{E}_{1 \mathrm{u}}$ states named after the benzene nomenclature $\left(\mathrm{D}_{6 \mathrm{~h}}\right.$ symmetry). These states are referred in the literature as the $S_{1}, S_{2}$ and $S_{3}$ singlet states respectively. ${ }^{9}$ Product studies of the photolysis of phenylsilane at $193 \mathrm{~nm},{ }^{5,6}$ which correspond to initial excitation of the $S_{3}$ state, indicate two primary photochemical dissociation channels: formation of benzene and silylene and formation of 
hydrogen and phenylsilylene, the latter being about six times more important than the former:

$$
\begin{array}{r}
\mathrm{PhSiH}_{3}-\cdots--->\mathrm{SiH}_{2}+\mathrm{PhH} \\
----->\mathrm{H}_{2}+\mathrm{PhSiH}
\end{array}
$$

Ishikawa and Kajimoto ${ }^{7}$ have studied the fragment energy distribution in the photolysis of phenylsilane at 248 and $193 \mathrm{~nm}$; absorption at these two wavelengths promotes the molecule to the $S_{1}$ and $S_{3}$ excited states respectively. In their work these authors explain the differences between the LIF excitation spectra of the $\mathrm{SiH}_{2}$ fragment from the difference in the total amount of excess energy at both wavelengths. Although differences in the distribution of energy in fragments produced in the multiphoton dissociation process were not considered, they concluded that the photolysis mechanism is the same at both wavelengths and operates through internal conversion from the initially excited singlet state to the ground state followed by dissociation. Recent thermal decomposition studies of phenylsilane support the latter conclusion. ${ }^{10}$ In order to get more insigt into the mechanisms that govern the UV photodissociation of the phenylsilane molecule, in the present work we have studied the photodissociation of phenylsilane following excitation of the molecule to its second excited singlet state $S_{2}$. Hence phenylsilane was photolyzed with a narrow band laser at the wavelength of $212.5 \mathrm{~nm}$ and the resulting photofragment fluorescence spectra were recorded in the spectral region from 200 to $900 \mathrm{~nm}$.

\section{EXPERIMENTAL}

The experimental set up has ben described in a recent publication ${ }^{11}$ and a short summary will be given here. The photolysis radiation was obtained by frequency doubling the output of a narrow band dye laser pumped by a $\mathrm{XeCl}$ excimer laser. The dye laser operating with Stilbene 3 dye is frequency doubled in a BBO crystal delivering typically $0.2 \mathrm{~mJ}$ of radiation at $212.5 \mathrm{~nm}$ with a bandwidth of $0.4 \mathrm{~cm}^{-1}$. The laser beam was focused with a quartz lens of $16 \mathrm{~cm}$ focal length at the center of a glass cell fitted with quartz windows which contained the flowing vapour samples. hotofragment fluorescence spectra were recorded with a $0.5 \mathrm{~m}$ monochromator (BM Spektronik) scanned with a step motor interfaced through a computer interface module (Stanford Research Systems SR245) with an IBM compatible personal computer. Light emerging from the exit window of the monochromator was viewed by an EMI 9816 QB photomultiplier which signal was fed into a gated integrator and Boxcar averager (SR250) or into a $40 \mathrm{MHz}$ digital oscilloscope (Tektronix 2430A) interfaced to the aforementioned personal computer for data storage and analysis.

Additional experiments were carried out with a different set up in which a molecular beam of phenylsilane was photodissociated with an ArF laser at $193 \mathrm{~nm}$. Details of this experimental system can be found in. ${ }^{12}$ In short, samples of phenylsilane vapour at room temperature were expanded to a vacuum chamber through a pulsed solenoid valve (General Valve Corporation, $0.05 \mathrm{~cm}$ of diameter). 
The output of an ArF excimer laser propagating perpendicularly to the molecular beam was focused about $1.5 \mathrm{~cm}$ below the nozzle; typical laser powers per pulse at the interaction region with the laser beam were estimated to be around $100 \mathrm{~mJ}$ $\mathrm{cm}^{-2}$. Spontaneous photofragment fluorescence from the interaction region was collected by a quartz lens, focused at the entrance slit of a $0.5 \mathrm{~m}$ Jarell-Ash monochromator and viewed by a photomultiplier (Hamamatsu R928). The signal from the photomultiplier was sent to the Boxcar and digitized by an a/d converter built into a programmable unit which allows control and proper timing of trigger pulses. ${ }^{13}$

The fluorescence cell was connected to a glass vacuum system which routinely operated at a vacuum of $10^{-5}$ Torr. Slow flowing samples of $\mathrm{PhSiH}_{3}$ vapour were introduced in the cell. Typical pressures, measured directly in the cell with a capacitance manometer (MKS Baratron $10^{-3}-1$ Torr), ranged between 200 and $300 \mathrm{mTorr}$. In the molecular beam experiments, phenylsilane stagnation pressures of 12 Torr were achieved by keeping the samples at room temperature. Phenylsilane was purchased from ABCR, its purity, measured by gas chromatography, resulted in a value of $99.4 \%$. Toluene and benzene purities as specified by the supplier (Prolabo) were $99.5 \%$ and $99.7 \%$ respectively. The liquid samples were carefully degassed prior to use. After several thousands of laser shots, both the windows of the glass cell and the windows of the molecular beam chamber were stained by a brownish deposit which had to be cleaned regularly in order to allow a proper propagtion of the photolysis beam right to the observation region.

\section{RESULTS}

Photofragment fluorescence spectra obtained by photodissociation of phenysilane at $212.5 \mathrm{~nm}$ were recorded in the 200 to $600 \mathrm{~nm}$ range. The spectra were recorded by measuring the total integrated fluorescence signal using a Boxcar gate width of $5 \mathrm{~ms}$. The observed emissons were assigned to several atomic lines of silicon, to the $\operatorname{SiH}\left(\mathrm{A}^{2} \Delta-\mathrm{X}^{2} \Pi\right) \Delta \mathrm{v}=0$ transitions and to the Swan bands of the $\mathrm{C}_{2}$ molecule corresponding th the $\mathrm{D}^{3} \Pi-\mathrm{a}^{3} \prod_{\mathrm{u}} \Delta \mathrm{v}=+1,0,-1$ transitions. As the fluorescence lifetimes of all the observed species are much shorter than the width of the gate, the intensity of the emissions can be interpreted as a measure of the relative state populations of the different fragments. Figure 1 shows the emission spectrum in the 200 to $400 \mathrm{~nm}$ region, taken with a resolution of $8 \AA$, with the assigned $\mathrm{Si}$ atomic lines. Emissions from 6 different $\mathrm{Si}$ excited states have been identified. ${ }^{14}$ Two of these states are triplets although the multiplet structure of the corresponding emissions cannot be seen with the present resolution. Due to the low pressures used in these experiments, not higher than $300 \mathrm{mTorr}$, time between collisions is a factor of ten longer than the typical lifetimes of the observed excited Si states. Therefore the fluorescence yield will not be significantly affected by quenching and the measured intensities can be correlated with the nascent populations that result from the photodissociation process. The populations of the Si levels which are the upper states of the observed transitions can be estimated by using the expression:

$$
\mathrm{N}=\left(\mathrm{g}_{\mathrm{u}} / \mathrm{g}_{1}\right) \mathrm{I} \lambda^{2} / \mathrm{f}
$$




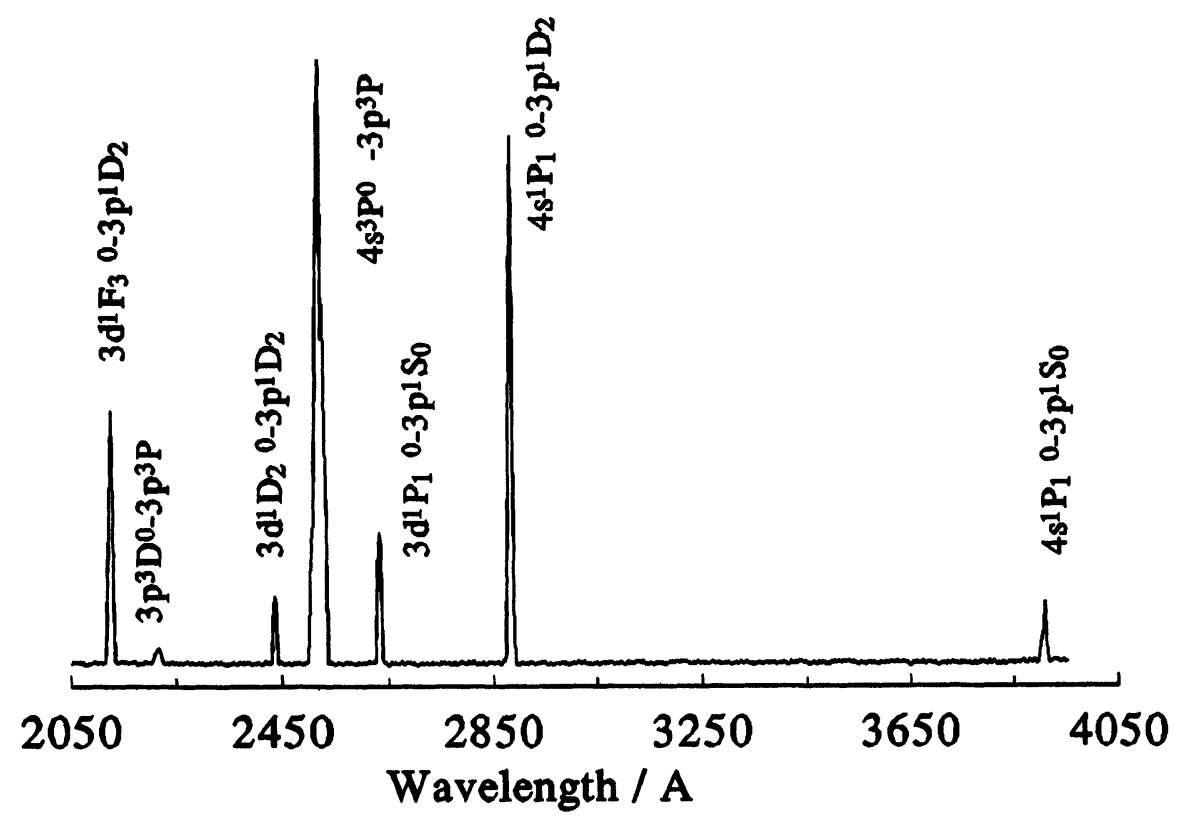

Figure $1 \mathrm{Si}$ atomic emission spectrum resulting from the $212.5 \mathrm{~nm}$ photodissociation of $200 \mathrm{mTorr}$ of phenylsilane. The spectral resolution is $8 \AA$. The spectrum has been approximately corrected by the response of the detection system.

where $g_{u}$ and $g_{1}$ are the degeneracies of the upper and lower level of the atomic transition respectively, $\mathrm{I}$ the measured intensity and $\lambda$ and $\mathrm{f}$ the wavelength and oscillator strength of the transition. Values for $\lambda$ and $\mathrm{f}$ have been taken from the literature. ${ }^{14} \mathrm{An}$ idea of the relative importance of the singlet to triplet $\mathrm{Si}$ emissions can be obtained by comparing the intensities of the singlet line $4 \mathrm{~s}^{1} \mathrm{P}_{1}{ }^{0}-3 \mathrm{p}^{1} \mathrm{D}_{2}$ at $288.1 \mathrm{~nm}$ and the triplet line $4 \mathrm{~s}^{3} \mathrm{P}^{0}-3 \mathrm{p}^{3} \mathrm{P}$ at $251.6 \mathrm{~nm}$. As a result of the comparison the population of the $4 \mathrm{~s}^{3} \mathrm{P}^{0}$ state is around 1.5 times higher than the population of the $4 \mathrm{~s}^{1} \mathrm{P}_{1}^{0}$ state. Lines observed at 263.1 and $212.4 \mathrm{~nm}$ correspond to $3 \mathrm{~d}^{1} \mathrm{P}_{1}^{0}-3 \mathrm{P}^{1} \mathrm{~S}_{0}$ and $3 \mathrm{~d}^{1} \mathrm{~F}_{3}^{0}-3 \mathrm{p}^{1} \mathrm{D}_{2}$ transitions respectively. The latter is around two times less intense than the former resulting in similar values of the population of the two corresponding upper states $3 \mathrm{~d}^{1} \mathrm{~F}_{3}^{0}$ and $3 \mathrm{~d}^{1} \mathrm{P}_{1}^{0}$. Another interesting feature of the $\mathrm{Si}$ emission spectrum in this experiment is the intensity of the singlet line at $243.5 \mathrm{~nm}$, which is higher than all other singlet emissions. This appears in marked contrast with observations performed in the photolysis of phenylsilane at $193 \mathrm{~nm}^{8}$ which results in a weak $243.5 \mathrm{~nm}$ line. In order to clarify the origin of this emission its intensity was monitored as the photolysis wavelength was tuned from 212.3 to $212.5 \mathrm{~nm}$. No appreciable variation was found, ruling out the participation of a resonant absorption process involving a $\operatorname{Si}\left(3 \mathrm{p}^{1} \mathrm{D}_{2}\right)$ atom.

In the region between 400 and $430 \mathrm{~nm}$ a strong emission corresponding to the $\mathrm{A}^{2} \Delta-\mathrm{X}^{2} \Pi \Delta \mathrm{v}=0$ band of the $\mathrm{SiH}$ fragment was observed. The spectrum in this 
region was taken with a resolution of $5 \AA$ and it is shown in Figure 2. When recording the spectrum a $320 \mathrm{~nm}$ cutoff filter (Hoya UV32) was placed in front of the entrance slit of the monochromator to avoid the presence of second order diffraction of the $\mathrm{Si}$ atomic lines. The rovibrational population distributions, which are responsible for the observed spectra, were estimated by using a computer program based on a truncated singular value decomposition method. ${ }^{15}$ The program uses reported molecular constants and transition energies which are available from the literature. ${ }^{16-19}$ The ratio of vibrational populations retrieved by the algorithm is $\mathrm{N}_{\mathrm{v}^{\prime}=1} / \mathrm{N}_{\mathrm{v}^{\prime}=0}=0.6 \pm 0.1$ and the average vibrational and rotational energies appearing on the $\operatorname{SiH}\left(\mathrm{A}^{2} \Delta\right)$ photofragment, calculated from the obtained rovibrational popultion distributions are $580 \pm 120 \mathrm{~cm}^{-1}$ and $2020 \pm 400 \mathrm{~cm}^{-1}$ respectively. The corresponding calculated spectrum is also shown in Figure 2. In order to compare these results with those reported in the literature for the photodissociation of phenylsilane at $193 \mathrm{~nm},{ }^{8}$ we repeated the experiment at $193 \mathrm{~nm}$ and analyzed the obtained $\operatorname{SiH}\left(\mathrm{A}^{2} \Delta-\mathrm{X}^{2} \Pi\right)$ emission with the algorithm mentioned above. The obtained ratio of vibrational populations $\mathrm{N}_{\mathrm{v}^{\prime}=1} / \mathrm{N}_{\mathrm{v}^{\prime}=0}$ is $0.9 \pm 0.1$ in good agreement with the value reported by previous authors. The average vibrational and rotational energies appearing on the $\mathrm{SiH}\left(\mathrm{A}^{2} \Delta\right)$ photofragment are $790 \pm 160$ and

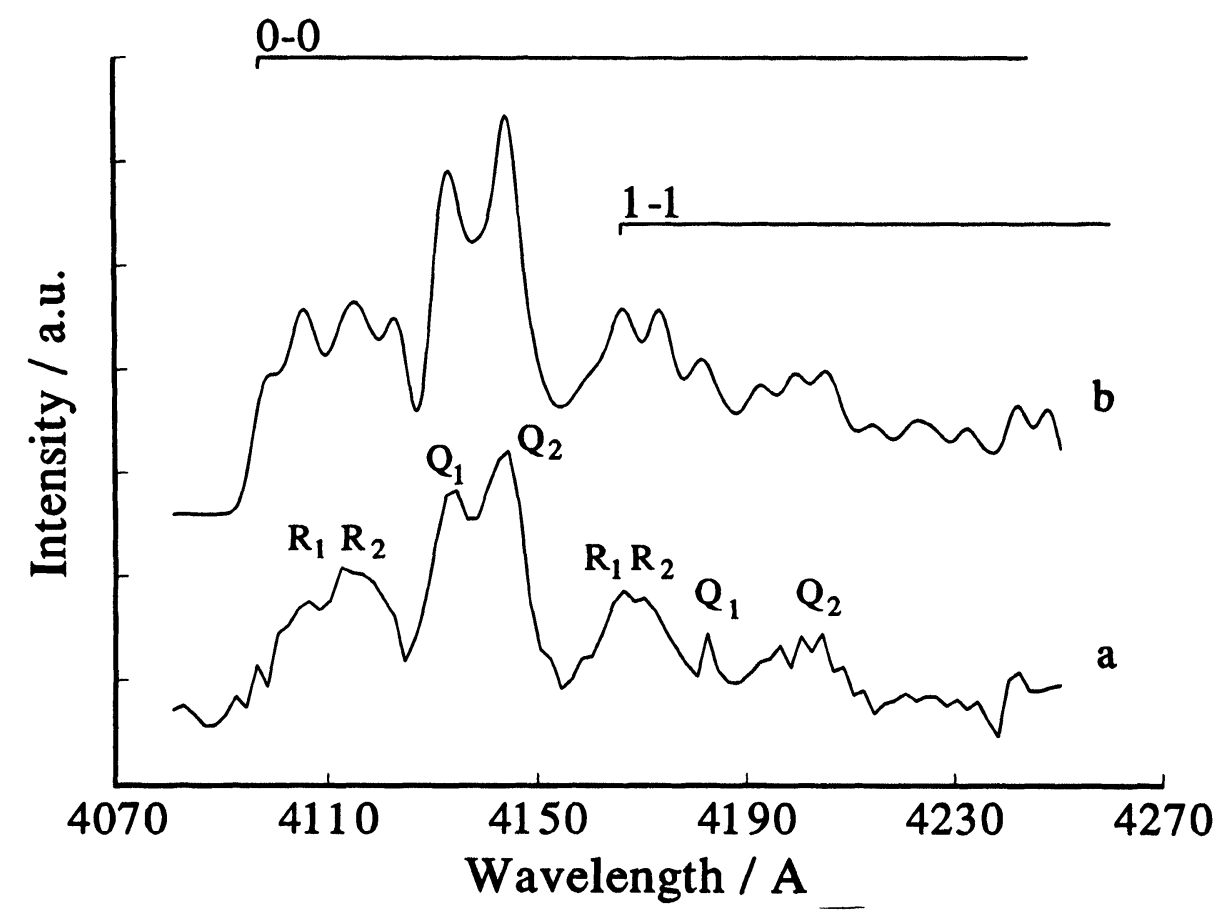

Figure $2 \operatorname{SiH}\left(\mathrm{A}^{2} \Delta-\mathrm{X}^{2} \Pi\right) \Delta \mathrm{v}=0$ photofragment fluorescence spectrum obtained by photolysis of phenylsilane with a resolution of $5 \AA$. a) Experimental spectrum taken in a flowing sample of $300 \mathrm{mTorr}$ of phenylsilane. b) Calculated spectrum with the corresponding ratio of vibrational populations and average vibrational and rotational energies. 
$2130 \pm 400 \mathrm{~cm}^{-1}$ respectively. These values are higher than those obtained at the dissociation wavelength of $212.5 \mathrm{~nm}$, reflecting the increase of available energy at $193 \mathrm{~nm}$.

In the region above $420 \mathrm{~nm} C_{2}\left(d^{3} \prod_{g}-a^{3} \prod_{u}\right) \Delta v=+1,0,-1$ Swan bands were observed at 470,515 and $560 \mathrm{~nm}$ respectively, their intensity being ten times lower than the intensity of the $\mathrm{SiH}$ emission. Figure 3 shows the spectrum of the $\Delta \mathrm{v}=+1$ Swan band with the assigned vibrational transitions taken with a resolution of $8 \AA$. Emissions from up to $v^{\prime}=6$ were assigned by using spectroscopic data available in the literature. ${ }^{20}$ The rovibrational populations which give rise to the observed spectrum were estimated by applying the algorithm mentioned earlier ${ }^{15}$ to the band sequence $\Delta v=+1$. The relative values for the vibrational populations of $\mathrm{v}^{\prime}=1$ to 6 levels are estimated in $1.0 / 0.8 / 0.7 / 0.5 / 0.4 / 0.3$, which results in an average vibrational energy of $4800 \pm 900 \mathrm{~cm}^{-1}$. Although the resolution of the experimental spectrum is not high enough to allow the determination of a rotational temperature for each vibrational level, it is possible to say that $\mathrm{C}_{2}\left(\mathrm{~d}^{3} \Pi_{\mathrm{g}}\right)$ fragments appear with a high content of rotational energy. The resulting calculated spectrum is also shown in Figure 3.

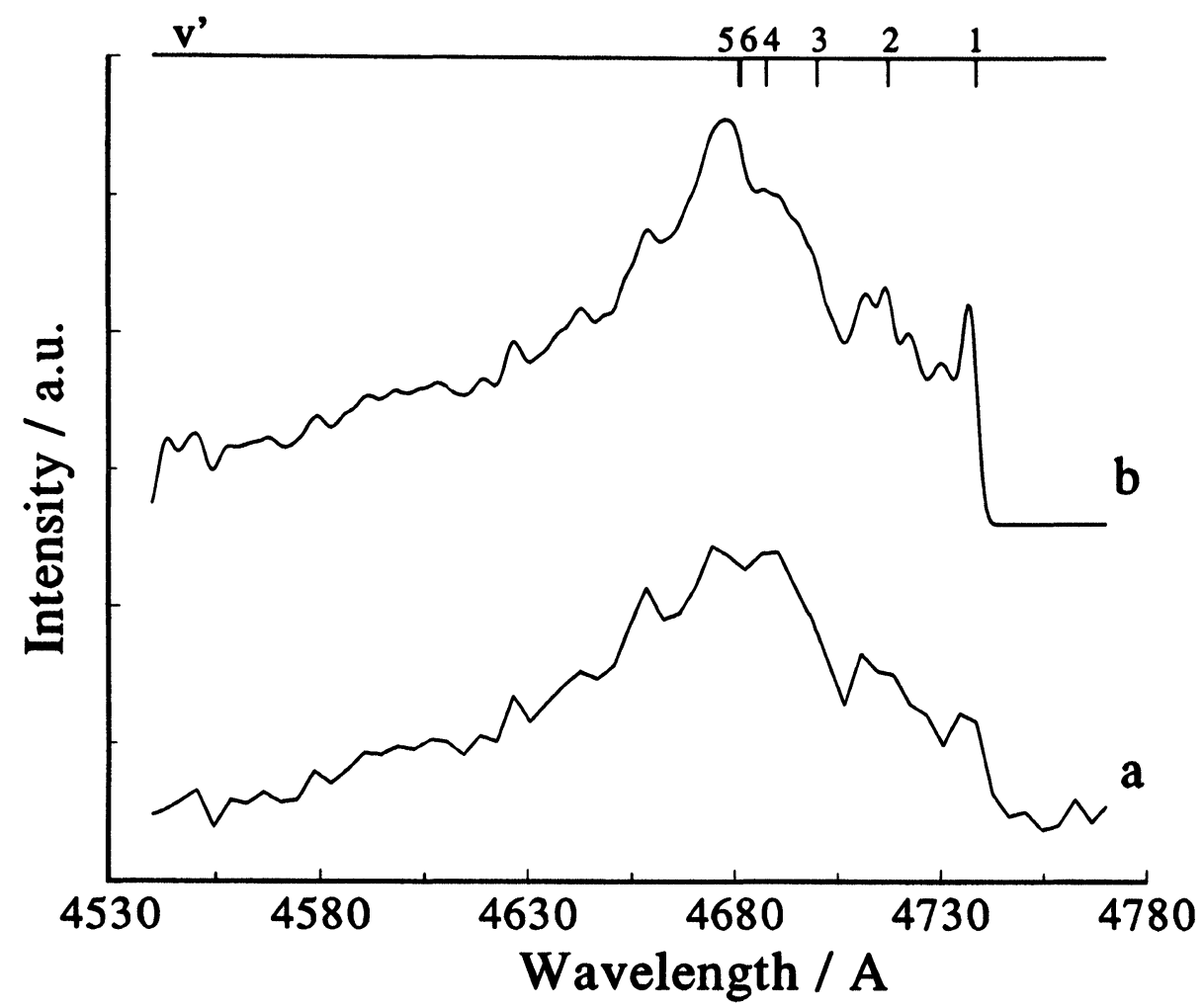

Figure $3 C_{2}\left(d^{3} \prod_{g}-a^{3} \prod_{u}\right) \Delta v=+1$ emission spectrum resulting from the $212.5 \mathrm{~nm}$ photodissociation of phenylsilane. The spectrum was taken with a resolution of $8 \AA$. a) Experimental spectrum obtained in a flowing sample of $300 \mathrm{mTorr}$ of phenylsilane. b) Calculated spectrum. 
On energy grounds, at least two $212.5 \mathrm{~nm}$ photons are required to form all the observed silicon states and the $\operatorname{SiH}\left(\mathrm{A}^{2} \Delta\right)$ molecule, and three photons are the minimum energy needed to produce $C_{2}\left(d^{3} \Pi_{g}\right)$. The dependence of each photofragment emission on the laser energy was investigated. Figure 4 shows the obtained results for $\operatorname{Si}\left(3 \mathrm{~d}^{1} \mathrm{~F}_{3}^{0}-3 \mathrm{p}^{1} \mathrm{D}_{2}\right), \operatorname{SiH}\left(\mathrm{A}^{2} \Delta-\mathrm{X}^{2} \Pi\right) \Delta \mathrm{v}=0$ and $\mathrm{C}_{2}\left(\mathrm{~d}^{3} \Pi_{\mathrm{g}}-\mathrm{a}^{3} \Pi_{\mathrm{u}}\right) \Delta \mathrm{v}=$ +1 emissions measured at $212.4,414.0$ and $465.0 \mathrm{~nm}$ respectively. The slope of the linear regression for the atomic emission is $1.8 \pm 0.2$ which indicates a quadratic dependence on laser energy; all other observed singlet emissions were found to display similar behaviour. The regression corresponding to the $\operatorname{SiH}\left(\mathrm{A}^{2} \Delta\right)$ photofragment has a slope of $2.2 \pm 0.2$ also compatible with a quadratic dependence on laser energy, whereas the slope for $C_{2}\left(d^{3} \Pi_{g}\right)$ emission is $3.4 \pm 0.3$ which corresponds to a cubic dependence on laser energy. As the observed emissions depend on laser energy as expected on energy grounds, it is possible to say that optical saturation of any of the steps participating in the multiphoton process is not taking place. Therefore the processes of formation of both $\mathrm{Si}$ atomic excited states and $\operatorname{SiH}\left(\mathrm{A}^{2} \Delta\right)$ photofragment involve two laser photons, whereas a three photon mechanism should be invoked for the production of the $\mathrm{C}_{2}\left(\mathrm{~d}^{2} \Pi_{\mathrm{g}}\right)$ photofragment.

Both atomic $\mathrm{Si}$ and molecular $\mathrm{SiH}\left(\mathrm{A}^{2} \Delta-\mathrm{X}^{2} \Pi\right)$ emissions have been reported in the $193 \mathrm{~nm}$ photolysis of phenylsilane. ${ }^{8}$ Regarding the $\mathrm{C}_{2}$ fragment, it has been suggested $^{3}$ that $\mathrm{C}_{2}$ molecules might be produced in the IRMPD of phenylsilane

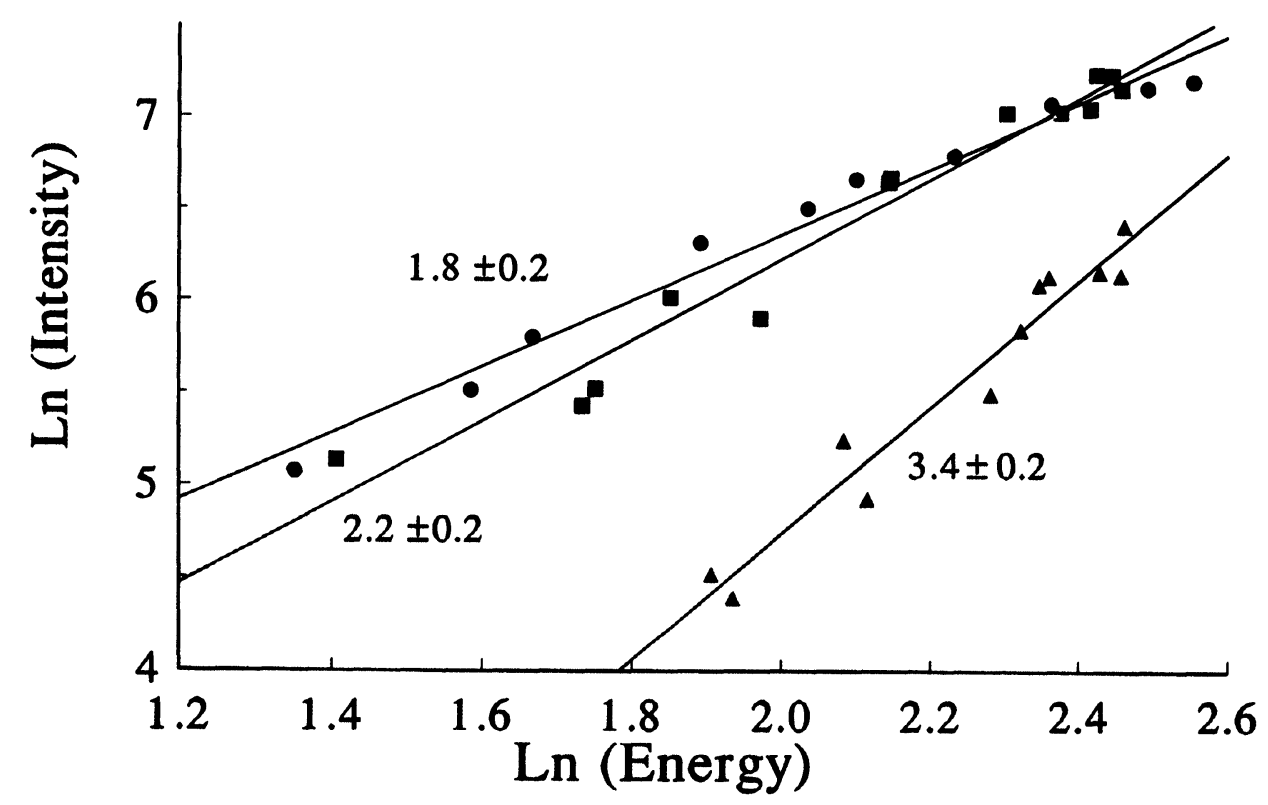

Figure 4 Logarithmic plots of the dependence of the observed photofragment emissions, obtained by $212.5 \mathrm{~nm}$ photolysis of $300 \mathrm{mTorr}$ of phenylsilane, with laser energy: $\operatorname{Si}\left(3 \mathrm{~d}^{1} \mathrm{~F}_{3}^{0}-3 \mathrm{p}^{1} \mathrm{D}_{2}\right), \mathrm{SiH}$ $\left(\mathrm{A}^{2} \Delta-\mathrm{X}^{2} \Pi\right) \Delta \mathrm{v}=0$ and $\mathrm{C}_{2}\left(\mathrm{~d}^{3} \Pi_{\mathrm{g}}-\mathrm{a}^{3} \Pi_{\mathrm{u}}\right) \Delta \mathrm{v}=+1$ emissions measured at $212.4,414.0$ and $465.0 \mathrm{~nm}$ and represented by circles, squares and triangles respectively. The slopes of the linear regressions are $1.8 \pm 0.2,2.2 \pm 0.2$ and $3.4 \pm 0.3$ respectively. 
accounting for the large amounts of carbon incorporated in films deposited from the photolysis of this compound. We attempted to observe $C_{2}$ production in the $193 \mathrm{~nm}$ photolysis of phenylsilane with the system previously described but no emission which could be attributable to the Swan bands was observed. In order to get more insight into the mechanisms that originate the observed $C_{2}$ photofragments in the phenylsilane molecule we studied the photofragment emission resulting from the photodissociaiton of toluene and benzene at $212.5 \mathrm{~nm}$. Very strong $\mathrm{CH}\left(\mathrm{A}^{2} \Delta-\right.$ $\left.\mathrm{X}^{2} \Pi\right) \Delta \mathrm{v}=0$ and $\mathrm{C}_{2}\left(\mathrm{~d}^{2} \Pi_{\mathrm{g}}-\mathrm{a}^{3} \Pi_{\mathrm{u}}\right) \Delta \mathrm{v}=+1,0,-1$ emissions were observed in the multiphoton dissociation of toluene. Although at the photodissociation wavelength of our studies the absorption coefficient of toluene is around two times lower than the corresponding value of phenylsilane, ${ }^{21}$ the Swan bands in the case of toluene are around 2.5 times more intense than those observed in phenylsilane. The dependence of this $\mathrm{C}_{2}\left(\mathrm{~d}^{3} \Pi_{\mathrm{g}}\right)$ emission resulting from the photolysis of toluene with laser energy was measured and found to be cubic as in the case of phenylsilane. On the other hand photolysis of benzene at $212.5 \mathrm{~nm}$ resulted in a weak $\mathrm{C}_{2}\left(\mathrm{~d}^{3} \Pi_{\mathrm{g}}\right)$ emission around seven times less intense that the corresponding emission of phenylsilane.

In order to confirm that the observed $\mathrm{C}_{2}\left(\mathrm{~d}^{3} \prod_{\mathrm{g}}\right)$ emissions were not the result of collisional processes or secondary reactions, their time resolved fluorescence was recorded; the fluorescence rises in a time limited by the risetime of the oscilloscope and decays monoexponentially. Decay lifetimes were pressure dependent and when extrapolated to zero pressure gave values about $100 \mathrm{~ns}$ in reasonable agreement with data reported in the literature. ${ }^{20}$

\section{DISCUSSION}

The possible two and three-photon mechanisms responsible of the appearance of the observed photofragments are discussed below. The observed Si emission spectrum shown in Figure 1 gives evidence of a highly selective distribution of population among the excited $\mathrm{Si}$ levels rather different than that observed when a molecular beam of $\mathrm{PhSiH}_{3}$ is photolyzed at $193 \mathrm{~nm} .^{8}$ Collisional deactivation of the excited parent or intermediate precursors could take place in the cell experiments and could be responsible for the differences observed with the distribution of Si states observed in the virtually collision free regime of the molecular beam experiments. However, as indicated above, in the pressure range of the present cell experiments, time between collisions is a factor of ten longer than the typical lifetimes of the excited Si levels making very unlikely the relaxation of the primary population distribution. Excited $\mathrm{Si}$ atoms could be produced by two possible channels: direct fragmentation of a twophoton excited parent molecule or fragmentation of an intermediate formed in the one-photon dissociation of $\mathrm{PhSiH}_{3}$, which subsequently has absorbed another photon prior to dissociation. The differences in the Si state distributions in the 193 and $212.5 \mathrm{~nm}$ photolysis would be difficult to explain by invoking the first mechanism via the parent molecule, as at such high levels of excitation a randomization of the available energy should be expected. In fact the high intensity of the $243.5 \mathrm{~nm}$ emission could be a signature of a process of the second type, involving one-photon resonant absorption of the laser radiation by an intermediate formed in the 
one-photon dissociation of the parent molecule. As mentioned earlier the two major channels in the UV photodissociation of $\mathrm{PhSiH}_{3}$ give rise to two different Si containing fragments, namely $\mathrm{SiH}_{2}$ and $\mathrm{PHSiH}$, that have to be considered as possible intermediates for the origin of the excited $\mathrm{Si}$ atoms. Again, differences observed in the 193 and $212.5 \mathrm{~nm}$ processes point out to the participation of a small size intermediate that would display different absorption features at these two wavelengths. At the laser wavelength of this study the energy available in process (1) is $74.2 \mathrm{kcal} \mathrm{mol}^{-1}$. $^{3,9,22}$ The content of internal energy of the $\mathrm{SiH}_{2}$ fragment, as determined in, ${ }^{8}$ should be a small fraction of the excess energy. Due to this fact there is not enough energy to explain the appearance of all the observed excited $\mathrm{Si}$ levels from the one-photon absorption process followed by dissociation of a common $\mathrm{SiH}_{2}$ precursor. Alternatively $\mathrm{PHSiH}$ radical, formed in process (2) with a high yield, could also be responsible of some of the Si observed emissions. The observed $\mathrm{Si}$ excited states population distribution could be the result of a process in which the participation of both intermediates could take place. Nevertheless the presence of other possible intermediates, such as $\mathrm{SiH}_{3}$ and $\mathrm{PHSiH}_{2}$, in the process of excited $\mathrm{Si}$ atom formation cannot be neglected, although their low quantum yield would make difficult to explain the strong atomic emissions observed in this experiment.

In contrast with the differences observed in the distribution of population among excited $\mathrm{Si}$ atoms, when the molecule is initially prepared in the $\mathrm{S}_{2}$ and $\mathrm{S}_{3}$ states at 212.5 and $193 \mathrm{~nm}$ respectively, the distribution of energy in the $\mathrm{SiH}$ fragment only changes slightly, although the experimental conditions at the two wavelengths are different and cooler distributions could be expected in the case of the molecular beam experiment at $193 \mathrm{~nm}$. The available energy in the two-photon process increases by $9510 \mathrm{~cm}^{-1}$ when the wavelength goes from 212.5 to $193 \mathrm{~nm}$, but the fraction of available energy appearing in internal excitation of the $\mathrm{SiH}$ fragment, estimated by means of the spectral simulation, only increases from $10 \%$ to $13 \%$, suggesting the idea that a common mechanism would be responsible of the appearance of the $\mathrm{SiH}$ fragment at both wavelengths. This result is similar to what is found regarding the $\mathrm{SiH}_{2}$ fragment in the photolysis of phenylsilane at 193 and $248 \mathrm{~nm}[8]$.

Production of $\mathrm{C}_{2}\left(\mathrm{~d}^{3} \Pi_{\mathrm{g}}\right)$ fragment appears to be a very selective process strongly dependent of the wavelength of the initial excitation. Similar effect was reported in the multiphoton dissociation of benzene. ${ }^{23}$ When photolysis is performed via the lowest singlet excited state $S_{1}$ at $248 \mathrm{~nm}$, emission from $\mathrm{C}_{2}\left(\mathrm{~d}^{3} \Pi_{\mathrm{g}}\right)$ is detected, however no measurable radical fluorescence is obtained when photolysis proceeds via the $S_{3}$ state at $193 \mathrm{~nm}$. These differences have been discussed ${ }^{24}$ in terms of the relative participaiton in the photodissociation process of the molecular ion and the neutral fragments. The fact that Swan bands are observed in the multiphoton dissociation of $\mathrm{PhSiH}_{3}$, toluene and benzene at $212.5 \mathrm{~nm}$ could be an indication that a common precursor is participating in the formation of the $\mathrm{C}_{2}$ fragment.

Although in this work only a small fraction of the overall products are being monitored by detecting fluorescent photofragments, a few conclusions can be drawn regarding the multiphoton dissociation process of phenylsilane following initial excitation on the $S_{2}$ and $S_{3}$ states at 212.5 and $193 \mathrm{~nm}$ respectively. These two processes display some differences which affect the distribution of population of 
atomic $\mathrm{Si}$ excited states and the formation of $\mathrm{C}_{2}\left(\mathrm{~d}^{3} \Pi_{\mathrm{g}}\right)$ radical by a three-photon process, only observed when $\mathrm{PhSiH}_{3}$ is photolyzed at $212.5 \mathrm{~nm}$. On the contrary, the content of internal energy of the $\operatorname{SiH}\left(\mathrm{A}^{2} \Delta\right)$, formed in a two-photon process at both wavelengths, sems to reflect the increase of available energy in the photolysis.

\section{Acknowledgements}

This work was supported by Spanish DGICYT (PB93-0145-C02-01) and by the Human Capital and Mobility Programme of the European Community (CHRXCT94-0485). The assistance of Dr. J. Ruiz in the spectral simulations is gratefully acknowledged.

\section{References}

1. J. S. Francisco, S. A. Joyce and J. I. Steinfeld, J. Phys. Chem. 88, 3098 (1984).

2. J. W. Thoman Jr. and J. I. Steinfeld, Chem. Phys. Lett. 124, 35 (1986).

3. J. I. Steinfeld, Spectroquim. Acta 46A, 589 (1990).

4. G. Inoue and M. Suzuki, Chem. Phys. Lett. 105, 641 (1984).

5. J. E. Bagott, M. A. Blitz, H. M. Frey, P. D. Lightfoot and R. Walsh, Chem. Phys. Lett. 135, 39 (1987).

6. M. A. Blitz, H. M. Frey, F. D. Tabbott and R. Walsh, J. Phys. Chem. 94, 3294 (1990)

7. A. Ioannidou-Philis and A. A. Christodoulides, Z. Phys. D 16, 271 (1990)

8. H. Ishikawa and O. Kajimoto, J. Phys. Chem. 98, 122 (1994).

9. A. Ioannidou-Philis, J. G. Philis and A. Christodoulides, J. Mol. Spectry. 12, 50 (1987).

10. H. E. O'Neal, M. A. Ring, D. Kim and K. D. King, J. Phys. Chem. 99, 9397 (1995).

11. M. Castillejo, M. Martín, R. de Nalda and M. Oujja, Chem. Phys. Lett. 237, 367 (1995).

12. J. Ruiz and M. Martín, Chem. Phys. Lett. 226, 300 (1994).

13. M. Rodríguez, M. Martín and J . Ruiz, Meas. Sci. Technol. 3, 229 (1992).

14. A. A. Radzig and B. M. Smirnov, Reference Data on Atoms, Molecules and Ions (Springer Ser. Chem. Phys., Springer 1985).

15. J. Ruiz and M. Martin, Accepted for publication in Comput. Chem. (1995).

16. G. D. Rochester, Z. Phys. 101, 769 (1936).

17. A. E. Douglas, Can. J. Phys. 35, 71 (1957).

18. G. Herzsberg, A. Lagerqvist and B. J. Mckenzie, Can. J. Phys. 47, 1989 (1969).

19. M. Betrencourt, D. Boudjaadar, P. Chollet, G. Guelachvili and M. Morillon-Chapey, J. Chem. Phys. 84, 4121 (1986).

20. M. Martín, J. Photochem. Photobiol. A: Chem. 66, 263 (1992).

21. A. Bolovinos, J. Philis, E. Pantos, P. Tsekeris and G. Andritsopoulos, J. Mol. Spectry. 94, 55 (1982).

22. A. Yokoyama, X. Zhao, E. J. Hintsa, R. E. Continetti and Y. T. Lee, J. Chem. Phys. 92,4222 (1990).

23. C. T. Lin, Ph. Avouris and Y. J. Thefaine, J. Phys. Chem. 86, 2271 (1982).

24. Y. Mori and T. Kitagawa, Bull. Chem. Soc. Jpn. 66, 1043 (1993). 